\title{
Realidade, criatividade e imaginário na teoria dos tipos psicológicos de Jung
}

\author{
Reality, creativity and the imaginary in Jung's psychological types
}

\section{Gustavo Monteiro Pessoa de Andrade}

[a] Psicólogo, Mestrando no Programa de Psicologia da Educação e do Desenvolvimento Humano na Universidade de São Paulo (USP), São Paulo, SP - Brasil, e-mail: gustavo.pessoa@usp.br

\section{Resumo}

Neste trabalho, pretendeu-se conduzir um estudo teórico acerca das concepções de realidade, imaginação e percepção do mundo a partir da teoria dos tipos psicológicos de C. G. Jung. Levantamos temas relevantes na atualidade como a relação com o corpo, o cotidiano, o uso da internet e o paradigma científico contemporâneo. Buscou-se, por meio desses exemplos, mostrar que a relação com a realidade concreta pode ser tão criativa quanto o uso da imaginação e das intuições, embora não haja evidências dessa forma de criatividade na contemporaneidade. Por outro lado, a desvalorização do concreto, do real e do material pode trazer questões ao desenvolvimento psicológico do indivíduo, como disfunções na relação com o corpo e uma vivência sem parâmetros da virtualidade experimentada nas relações mediadas pela internet. Argumenta-se que é necessário revisar a associação comumente feita entre criatividade, intuição e imaginação. Resgatando a ideia de totalidade e o conceito de numinosidade presentes na obra de Jung, discutiu-se a questão do viver e articular diferentes modos de percepção do mundo, o que inclui tanto a imaginação como a materialidade e o mundo sensível, considerando possível o exercício da criatividade em ambas as formas de perceber. Desse modo, de acordo com a noção de totalidade, buscamos um melhor modelo de desenvolvimento psicológico saudável.

Palavras-chave: Realidade. Imaginação. Criatividade. Jung. Tipos psicológicos.

\begin{abstract}
The present work intended to conduct a theoretical study about the conceptions of reality, imagination and perception using Jung's psychological types theory. We have discussed relevant themes in contemporaneity such as the relationship with one's body, everyday life, internet use and the current scientific paradigm. The goal of this discussion was showing that the relationship with concrete reality might be as creative as the use of imagination and intution, even though there is no evidence that such form of creativity is being stimulated in contemporaneity.
\end{abstract}


However, depreciation of what is concrete, material and real might bring up questions such as dysfunctions in one's relationship with their bodies and a limitless experience of virtuality in relationships that use internet as their medium. We thus argue that it is necessary to revise the common association between creativity, intuition and imagination. Using Jung's concept of totality and numinosity, we have discussed how to experience and articulate different forms of perceiving the world, which must include both imagination and materiality and the sensible world. We must consider it possible to perceive the world in both ways in order to think of a more healthy psychological development for the individual.

Keywords: Reality. Imagination. Creativity. Jung. Psychological types.

\section{Introduçáo}

A origem deste artigo se situa em um incômodo sofrido provavelmente por aqueles que passam inúmeras dificuldades em sua vivência com a matéria. Embora essa relação seja muitas vezes subestimada, estamos cercados por tudo aquilo que possui existência imediata; as coisas palpáveis e visíveis, os cheiros e sons incessantes e a concretude de um mundo que não nos ilude com a ideia de que sempre seremos satisfeitos em nossos desejos. Durante muito tempo, a esse mundo foi dado o nome de realidade. Ser realista ou tornar-se mais realista significou, durante muitos anos e ainda hoje, a capacidade de averiguar e ponderar aquilo que a percepção de nossos sentidos nos diz. As "chances reais" de algo acontecer são, na verdade, uma ponderação de um passado e um presente de nossa realidade material. O mais provável, comumente, relaciona-se com a frequência com que algo se concretiza.

Na psicologia, é também frequente adotarmos uma posição mais intuitiva. Estamos preocupados com o futuro e o vir-a-ser. A fantasia nos interessa, os sonhos são nosso material de trabalho e também parecemos gostar do uso de recursos expressivos que permitam uma análise ou discriminação de algo que o paciente ainda não consegue ver. É também comum, em suas vidas pessoais, muitos psicólogos apresentarem certa dificuldade em lidar com aquilo que é material. Organizar-se diante de muitas contas a pagar, orientar-se espacialmente com precisão e ter a capacidade para discriminar com sofisticação sabores, cheiros e detalhes constitui um conjunto de habilidades difíceis para alguns profissionais em suas experiências privadas.

Torna-se, portanto, relevante que estudemos, a partir de uma perspectiva crítica, aquilo que Jung ([1921] 2009) denominou como função sensação. As funções da consciência para esse autor são quatro e formam uma tipologia básica que nos apresenta estas questões a respeito do funcionamento do ego: há uma orientação mais conceitual ou mais avaliadora? $\mathrm{O}$ indivíduo tem um olhar mais global ou mais detalhista em sua percepção?

Para essas perguntas, a tipologia pode oferecer algumas direções. A função sensação, nessa teoria, relaciona-se àquilo que é: o mundo da matéria. Cabe a essa função da consciência apontar a existência concreta de algo. As outras funções, nominalmente a intuição, o pensamento e o sentimento, relacionam-se aos insights e a antever possibilidades ainda encobertas, conceituar o que algo é e conferir valor e avaliar alguma coisa, respectivamente.

Este trabalho pretende olhar com mais cuidado para as possibilidades de desenvolvimento criativo da sensação. É muito comum valorizarmos fantasias, visões e sonhos. Parece menos frequente, contudo, que vislumbremos criatividade no lidar com a realidade material. Aquilo que é, geralmente, é visto como algo ameaçador ou castrador de nossas fantasias, pronto para interromper um processo vital e feliz do homem. Para esse tipo de pensamento, este artigo é uma resposta forjada com base em difíceis reflexões, muitas referências e grandes obstáculos. Não se pretende responder definitivamente, mas provocar uma reflexão e oferecer um ponto de vista que possa, ainda que de maneira limitada, prover um modo de se pensar o concreto diferente do raciocínio mais comum. É nosso objetivo, também, dar valor a uma dimensão dificilmente escolhida como foco criativo na psicologia. Nesse sentido, propomos um pensamento na direção oposta, buscando integrar à consciência algo que permita que saiamos da unilateralidade de uma posição rígida a respeito do que favorece criativamente o ser humano. Espera-se, dessa forma, poder desvelar 
uma discussão importante para o desenvolvimento da consciência em nossa época.

\section{O mundo sensível}

A palavra sensivelsignifica, a partir do estudo etimológico do vocábulo, aquilo que é pertinente ao sentimento e aos sentidos. Seguindo a etimologia, curiosamente, sensibilidade alude ao fato de sermos organismos capazes de sentir tanto sensações como emoções. Segundo o Dicionário Houaiss (2001), radical sens- tem sua origem no latim e significa "experimentar através dos sentidos". O radical sentvem dessa mesma língua e traduz a mesma coisa, adicionando "tornar-se ciente de", "ser afetado por" e "fazer total uso dos sentidos e das faculdades".

$\mathrm{Na}$ perspectiva biológica, os sentidos são cinco e estão fundamentalmente ligados à capacidade de captar determinados estímulos e traduzi-los em determinados significados para que o organismo possa tomar certas medidas adaptativas de acordo com o ambiente no qual se encontra. Dessa forma, uma queda brusca e intensa de temperatura será captada por determinadas estruturas da pele, que devem transmitir essa informação para o cérebro, possivelmente fazendo com que um determinado indivíduo busque se agasalhar ou se deslocar para um ambiente em que a condição térmica seja mais confortável para ele.

Jung ([1912] 2004a) considerou a função sensação de modo semelhante em sua perspectiva psicológica. Também é tarefa da função sensação, como função da consciência do indivíduo, identificar o que uma coisa é, pois capta todos os estímulos, recebe e traduz aquilo que é experimentado no mundo. É dela a missão de nos dizer aquilo que é real e concreto. $\mathrm{O}$ autor se apressa em explicar que é de outra função dizer o que algo é; a função sensação tem como característica admitir a existência e nos mostrar que as coisas ali estão. É a capacidade humana de reconhecimento de seu ambiente antes de fazer o processamento daquilo que foi reconhecido. A conceituação daquilo que foi identificado cabe ao que Jung definiu como função pensamento.

Em sua explanação, o autor afirma que a sensação compõe um eixo e um par com a função intuição. Ao contrário da sensação, Jung coloca a função intuição como aquela que capta o que não está lá. A intuição antevê; traz um insight. Em outro momento, Jung ([1921] 2009) nos diz que a intuição é uma percepção do inconsciente. Seu funcionamento é obscuro, trazendo à tona, de modo incompreensível, aquilo que estava no reino do desconhecido. Desse modo, cria-se uma oposição entre o visível e o invisível, a existência imediata e a existência latente, aquilo que é e aquilo que está prestes a ser. A sensação coloca o presente à disposição; a intuição adianta o futuro para o indivíduo.

Uma segunda característica do par sensação/intuição colocada por Jung é a de que se trata de funções irracionais. Sobre esse termo, Jung ([1921] 2009, p. 352) afirma: "denomino irracionais os dois tipos acima, porque seu fazer e deixar de fazer não se baseiam em julgamentos racionais, mas na força absoluta da percepção. Esta se dirige simplesmente para o que acontece, sem escolha judiciosa". Irracional não é, portanto, sinônimo de inconsciente. Embora esse esclarecimento seja frequentemente relembrado, parece-nos que ainda permanece a confusão. Constantemente, temos a impressão de que a função sensação é sempre colocada como aquela que está consciente. Os exemplos falam por nós: cita-se essa função quando alguém se mostra muito observador, quando exalta algum dos cinco sentidos ou faz um apontamento intensamente detalhista sobre uma determinada coisa. É claro que, em todos esses exemplos, é necessário que se esteja consciente para que tais eventos ocorram. Contudo, é necessário enfatizar e reenfatizar que a função sensação é uma função irracional e não uma função necessariamente consciente ou inconsciente. A sensação é parte de um eixo de duas pontas: se em uma extremidade temos a intuição, na outra encontramos a sensação. Portanto, uma extremidade consciente da intuição implica uma sensação inconsciente na mesma medida.

O pareamento entre as funções sensação/ intuição nada faz para solucionar o possível desentendimento. É igualmente comum que seja necessário diferenciar "irracional" de "inconsciente" quando falamos em função intuição, a qual, pela definição dada por Jung ([1921] 2009), já se conecta ao conteúdo inconsciente para informar aquilo que ainda não é. Contudo, quando se fala em função sensação, evoca-se a ideia oposta, fazendo a equivalência, ainda que não se perceba, entre a percepção do real e o conceito de consciência. O que parece estar implícito na colocação do autor da "força 
Andrade, G. M. P. de.

absoluta da percepção" é uma captação involuntária, tal como acontece fisiologicamente pelo organismo humano em perfeita condição, dos estímulos físicos externos. Esses estímulos pertencem ao mundo, no caso da função sensação, e portanto estão ligados aos sentidos. Contrariamente, pertencem ao inconsciente quando falamos em função intuição. Tanto o mundo como o inconsciente constituem um outro, um estímulo externo e desconhecido que é captado pela "força absoluta da percepção" antes que o eu racional possa fazer qualquer julgamento acerca do material captado. Não se pode escolher, julgar ou conceituar a percepção do frio ou do calor, tampouco se pode impor a um insight tais ações; tanto o frio, a fome ou o insight simplesmente acontecem à revelia da vontade ou da intenção. É disso que se trata a percepção.

A etimologia, porém, trata o radical senstanto do ponto de vista da percepção quanto da consciência. Não apenas o mundo sensível é aquele captado pelo sentido, mas tal captação também inclui o “tornar-se ciente de". É verdade, também, que as sensações intensas parecem irromper na consciência involuntariamente. Em algum momento, o corpo emite para a consciência sinais inequívocos de que são necessários o sono, a alimentação, a aproximação, o distanciamento, o contato, o resfriar-se e/ ou aquecerse. Psicologicamente, contudo, há a possibilidade de qualquer uma das quatro funções psicológicas apresentadas por Jung ([1921]2009) estarem inconscientes, na medida em que sua função complementar estará consciente. O que se pode levantar aqui é a hipótese de que as funções irracionais não são necessariamente conscientes, mas em sua dinâmica parece haver um movimento de "tornar-se ciente de". A percepção busca informar a pessoa do que se passa ao seu redor; contudo, esse movimento pode ser impedido pelo próprio funcionamento psíquico do indivíduo, de acordo com sua vivência naquele momento. Von Franz (2004) traz um exemplo justamente de um tipo de intuição na consciência, consequentemente tendo a função sensação como seu par inconsciente. A autora relata que uma das maneiras de aproximação da sensação para um intuitivo são os trabalhos manuais, comumente ligados à matéria, ao concreto, àquilo que existe imediatamente. $\mathrm{O}$ agir na realidade coloca o intuitivo em contato com seu funcionamento perceptivo mais inconsciente representado pela função sensação.
À função mais inconsciente se dá o nome de função inferior, e aquela mais consciente é chamada de função superior. No exemplo citado, ter a sensação como função inferior significa uma ameaça de invasão da sensação a qualquer momento. É um processo difícil e extenuante para um indivíduo lidar com sua função inferior, e fundamentalmente um caminho lento, o que costuma gerar no eu certa aversão por trabalhar com essa função. Não se pode afirmar que a sensação é sempre consciente; ao contrário, essa função, assim como qualquer uma das outras três, pode tanto ser a função superior e consciente de um indivíduo quanto sua função inferior e, portanto, inconsciente (Von Franz, 2004).

Um dos pontos que parece levar à confusão entre sensação, intuição, consciência e inconsciente jaz na maneira como as duas funções irracionais atuam. Como visto, a função sensação age como um intermediário poderoso com o mundo. Estamos falando do mundo concreto que está lá fora, o mundo das coisas, repleto de cheiros, gostos e paisagens, o contato com o corpo, a sensualidade, as impressões sensoriais. O eu toma conhecimento desse mundo sensível fundamentalmente a partir das sensações, seja em uma perspectiva psicológica ou biológica, no caso da separação ser necessária.

A função intuição, ao contrário, age como mediadora dos conteúdos inconscientes. Na consciência, é o funcionamento mais próximo do sonhar, imaginar e devanear. Ela potencializa e dá suporte ao processo simbólico de pensamento, reflexão e amplificação. Faz conexões sem lógica imediata e traz apoio ao conceito de sincronicidade, uma vez que não constrói relações entre as coisas nem a partir do pensamento formal, nem a partir da existência concreta. A sensação não responde a esses tipos de chamado; ela reside na matéria crua, nas obviedades do dado e do construído, da natureza tal como ela se apresenta aos sentidos. Contudo, devemos nos precaver contra a tentação de, sem nos darmos conta, compararmos o mundo sensível, concreto e imediato à consciência e o mundo do imaterial e do invisível ao inconsciente. Vale ressaltar que podem estar no inconsciente "inclusive as percepções subliminais dos sentidos" diz Jung ([1971] 2007, p. 2), isto é, as percepções captadas, mas não realizadas pela consciência. Desse modo, a consciência não é atributo da função sensação ou $\mathrm{o}$ inconsciente atributo da função intuição, ambas 
as funções foram definidas por Jung ([1912] 2004a) como funções da consciência.

\section{A cabeça e o corpo}

A pós-modernidade, considerada como a época atual, traz uma nova perspectiva e um novo paradigma científico para a humanidade, como afirma Hauke (2003, p. 30). Na visão pós-moderna, as polaridades são admitidas e buscamos dar um lugar possível para a alteridade, tentando lidar com diversas possibilidades de olharmos para o mesmo fenômeno sem termos de caracterizar necessariamente uma como certa e outra como errada. Por isso, Hauke atribui a esse período algumas palavras que trazem o sentido da nova época: local, fragmentado, perspectiva, abstrato, subjetivo, muitos.

Apesar dessa conduta em admitir e tentar encontrar lugar para o diferente, parece um desafio considerável lidar com a função sensação diante do novo paradigma. Os termos "abstrato", "subjetivo", "perspectiva" e alguns outros são estranhos ao conhecimento popularmente atribuído à seara sensorial. As atividades praticadas pelo homem nesse contexto histórico tampouco: o plantador de batatas que sentia a terra úmida em suas mãos hoje é substituído por um trator; as tarefas mais valorizadas estão voltadas para números, telas de computadores e balanços corporativos que são, na melhor das hipóteses, expressões virtuais de atividades praticadas enquanto o corpo concreto passa o dia inteiro sentado atrás de uma cadeira. Até mesmo o suposto dinheiro produzido por grandes empresas multinacionais atinge uma cifra tal que, concretamente, nunca será visto na frente de qualquer ser humano de carne e osso. Ele existe apenas na abstração de nosso sistema econômico. Nessa cultura, porém, ainda é considerado com estranhamento que exista uma epidemia de obesidade no mundo, deixando clara a dificuldade coletiva em estabelecer limites para o corpo e administrar sua realidade física.

A ciência pós-moderna, tal como a cultura e o mercado, também parece ter passado a considerar os ditames de outras funções além da sensação. Embora tenhamos comemorado o centenário do nascimento de Charles Darwin em 2009, os grandes cientistas parecem não ser mais aqueles que empreendem viagens reais e se dedicam à observação da natureza tal como ela ocorre. São necessariamente intermediados por computadores e aparelhos em busca de um refinamento em seu conhecimento. Mais do que isso, contudo, parece relevante apontar que a era inaugurada por Einstein nos revela a valorização de outro tipo de funcionamento: quando o grande físico nos diz que "imaginação é tudo" e surge um movimento no qual a física quântica e a psicologia parecem ter mais pontos de aproximação do que duas outras áreas quaisquer das ciências naturais, o tom de fantasia e criatividade imaginal da função intuição está presente.

Von Franz (2004) caracteriza a intuição como uma função mais disposta à fantasia e à imaginação. Se perguntarmos para alguma pessoa na rua qual sua imagem de cientista, não nos surpreenderíamos se ela nos relatasse a cena de um homem à frente de uma lousa ou um computador com uma grande equação, esperando um insight para resolvê-la, utilizando prontamente o pensamento e a intuição. Contudo, à época de Darwin e Mendel, era provavelmente à frente de uma grande paisagem que os cientistas se colocavam. Não é por acaso que junto a Darwin tenha se imortalizado a imagem da tartaruga, tal como Newton nos evoca a maçã e Mendel nos fala sobre uma ervilha. Não nos parece que a paisagem ou a coisa concreta fornecesse insight para o cientista desprovido do contato com o real, ao modo da intuição; naqueles casos, ao contrário, foi no contato por meio da sensação que o conteúdo inconsciente emergiu, por intermédio do detalhe e da impressão sensorial, permitindo a pesquisa e a descoberta.

$\mathrm{Na}$ esfera do trabalho, novos conceitos parecem se aproximar mais da intuição e se distanciar da sensação. De Masi (2000) apresentou seu conceito sobre ócio criativo, afirmando ser necessário um período de pausa para que possamos exercer a criatividade. Nesses períodos, embora o corpo físico esteja em repouso, a imaginação e o pensamento simbólico estão em plena atividade. Lehman (1999) defende o ócio e nos diz que os períodos de não atividade podem ser usados para o fantasiar e o imaginar como uma maneira de escapar do mundo asfixiante da produção apresentado pelo trabalho. A atividade mecânica e laboriosa, cuja finalidade está em produzir necessariamente algo concreto, ainda que seja uma concretização de pensamentos nos inúmeros relatórios requeridos em diversos setores do mercado de trabalho, é caracterizada como algo que impede ou nega a diversão, a reflexão e o encontro 
do indivíduo consigo mesmo. O termo "linha de produção" ganhou conotação pejorativa desde a cena clássica de Tempos modernos (1936), em que Chaplin faz alusão à alienação provocada por movimentos repetitivos e sem sentido na perspectiva do operário.

Embora aos trabalhos manuais não se atribua tal negatividade, as artes plásticas e algumas atividades como o trabalho em madeira, cerâmica ou costura são tidos mais como hobbies ou profissões de baixa remuneração, requerendo igualmente baixa qualificação na maioria dos casos. É interessante notar também que os grandes artistas e designers que fogem à regra são comumente considerados talentosos, agraciados por algum deus ou detentores de algo genético, inato ou sobrenatural de alguma espécie. A "mágica" do talento significa que ou ele está ali ou não está. Não existe sobre ele reflexão ou possibilidade de desenvolvê-lo no caso de não se apresentar para a consciência a priori. Ele é tomado como algo material e inegável, transformando o concreto em concretismo.

Nesse sentido, lançamos algumas das atividades que incluem a função sensação em uma consciência mágica, como colocada por Whitmont (1991, p. 63), encerrando a capacidade de fazer algo em uma classificação supostamente real e indiscutível, com ou contra a qual nada se pode fazer, tal como as sociedades ditas primitivas consideravam seus mitos. Em outras palavras, para muitos de nós a função sensação tornou-se um mistério, retornou ao inconsciente, ao desconhecido, em grande medida. O talento e a pessoa são uma coisa só e não há espaço para discussão, em uma tentativa de conceituação e debate, ou treinamento, se pensarmos no exercício da sensação com o objetivo de desenvolvê-la. E como parecemos apreciar e nos surpreender com pequenas crianças que logo demonstram "ter ouvido" para a música! E como nossa função sensação permanece, dessa maneira, em uma dinâmica psíquica menos desenvolvida.

O que parece acontecer é uma confusão entre o que Jung ([1921]2009) adequadamente apontou como irracional e aquilo que é mágico, fusionado ou inexplicável. A função sensação é uma função irracional, mas de maneira nenhuma algo mágico. Pode, entretanto, estar se tornando mais inconsciente na coletividade à medida que temos resgatado o valor da intuição. Deve-se ressaltar, nesse sentido, que tudo aquilo que desobedece à lógica da racionalidade ou do julgamento não é, por isso, algo incompreensível, inexplicável ou mágico. Essa discussão parece apontar, portanto, para a necessidade de produção de pesquisas exatamente nesse entrecruzamento entre o irracional, o inexplicável e o inconsciente, três fatores que claramente não podem ser usados como sinônimos.

Não se trata de defender uma posição ou outra quando nos deparamos com a intuição e a sensação. Tampouco nos posicionaríamos contra a capacidade conceitual da função pensamento. É claro que, sem a abstração e a imaginação necessárias nas ciências naturais, dificilmente poderíamos estudar algo tão invisível aos nossos olhos como o genoma de uma mosca, um determinado alelo de nosso código genético ou um choque entre prótons. É também inegável o componente intuitivo em uma série de modalidades artísticas e de trabalhos manuais. No entanto, é natural que a necessária revalorização da intuição nos afaste da concretude do mundo das sensações: os aromas naturais vão sendo paulatinamente substituídos pelos artificiais e nossa alimentação se tornando cada vez mais sintética, já que a sofisticação do paladar, por exemplo, precisa dar lugar a um refinamento de uma função oposta que possa trazer os insights necessários ao suposto avanço de nossa espécie.

Também dessa maneira o trabalho dos sentidos, incluindo a miríade de manifestações artísticas - como o cantar, o dançar e o esculpir -, obviamente pautadas pelo funcionamento dos sentidos, torna-se algo mais difícil de compreender e possivelmente mágico ou divino. É desse modo, contudo, que o mundo da matéria e aquilo representado pela sensação tornam-se um pouco mais inconscientes a cada passo que damos na ciência, na cultura ou na economia em direção ao desenvolvimento da intuição. Também nosso funcionamento consciente segue se transformando de acordo com o princípio da compensação ou autorregulação (Jung, [1966] 2002).

Além de uma ciência inclinada à valorização da função pensamento e da função intuição em detrimento do sentimento e da sensação, nossa vivência atual parece também falar diretamente de uma relação particular com o corpo, desenvolvida a partir das premissas pós-modernas e do mecanismo da autorregulação. Jung ([1951] 1992, p. 2) admitiu as bases somáticas e as bases psíquicas do eu, acrescentando que muitas das sensações do corpo são subliminares ou inconscientes, e algumas provavelmente nunca se tornaram ou se tornarão conscientes. Em outro momento, o autor explicita que qualquer separação 
entre psique e corpo é uma necessidade conceitual ao se estudar o tema, mas afirma estarmos tratando essencialmente de dois lados de uma mesma coisa. Tanto a consciência do corpo como a consciência do eu psíquico são compreensões parciais. A totalidade da personalidade, o que incluiria ambas as bases do eu, é algo alcançado apenas quando também se considera a dimensão inconsciente da personalidade. A essa noção de totalidade, incluindo a consciência e o inconsciente, deu-se o nome de self (Jung, [1951] 1992).

Para Ramos (2006,p. 55), podemos também falar em self corpóreo: "a formação da imagem corporal não resulta apenas das experiências pessoais, mas baseia-se na relação entre o ego e o self, a qual também tem uma representação corpórea. A consciência corporal é um deintegrado; é a percepção de uma parte do corpo total, do self corpóreo". Dessa forma, também o corpo é uma experiência física apenas parcial, uma imagem passível de transformação. O corpo total, assim como a totalidade das sensações, é inacessível. Há, portanto, sempre uma dimensão inconsciente também naquilo que é tangível e concreto em nós mesmos.

\section{O real, o imaginário e o pós-moderno}

Bachelard (2006, p. 189), a propósito de descrever a que serve o devaneio, afirma que este "coloca o sonhador fora do mundo próximo, diante de um mundo que traz o signo do infinito". Sonhar, imaginar e devanear têm a característica comum de nos levar para longe de nossa habitação material corriqueira, portanto, afastando-se daquilo sobre o que a sensação trata. Desses processos, apenas a imaginação pode ser colocada como ao menos parcialmente consciente, sendo aquela em que, também, podemos apontar para uma função da consciência. A imaginação e a intuição têm relação entre si, ambas não podem prescindir do contato com o inconsciente. Resta-nos o questionamento se essa condição se aplicaria, efetivamente, também ao par sensação.

O que se usa aqui como real e pertencente ao reino da sensação merece uma discussão mais detalhada. É possível que, diante de parâmetros pósmodernos, o termo real não seja mais apropriado para descrevero que é trazido pela percepção dos sentidos e o contato com o mundo material obtido a partir da sensação. Hauke (2003, p. 240) nos aponta que a realidade é sempre vista a partir de uma determinada construção intelectual, o que nos obriga a revisar a ideia de que real é um sinônimo adequado para concreto, material ou sensorial. É verdade, contudo, que Jung ([1954] 2000) afirmara que o real não pode ser considerado apenas por sua parcela concreta imediata. A função sensação não existe sozinha, o que se cria como realidade é aquilo processado e elaborado pelas quatro funções da consciência e pela relação dessa consciência com o inconsciente. Todavia, deve-se examinar com cuidado a proposição de função sensação novamente para também não criarmos um sinônimo inadequado entre a realidade material e a função sensação, relegando o potencial imaginal e inconsciente novamente aos outros tipos psicológicos.

Hauke (2003, p. 245) prossegue sua exposição sobre a relação entre mente e matéria de acordo com o paradigma pós-moderno. Segundo o autor, a relação sujeito/objeto, melhor nomeada como observador/observado, é vista nos tempos atuais como uma relação entre um e outro. O observador, portanto, não pode se furtar de seu papel sobre aquilo que apreendeu; aquele que percebe afeta aquilo que foi percebido. Retornando à sensação como a possibilidade de percepção sensorial do mundo, colocamos a reflexão de que, ainda que irracional, a percepção é do indivíduo. Nesse sentido, ela é também única, particular e diz respeito àquele que pôde perceber o que quer que tenha sido percebido. A captação ou a não captação de determinado estímulo não é universal ou geral, sendo necessariamente particular e específica ao observador que procura perceber. Por isso, torna-se também delicada a tarefa de atribuirmos objetividade à sensação, mesmo ela versando aparentemente sobre o mundo material e a existência dada pelos sentidos orgânicos. Esses sentidos se apresentam, nessa perspectiva, como subjetivos e potencialmente simbólicos. É possível que exista um "porquê" e um "para que" na apreensão ou na tentativa de se ignorar determinados estímulos. É igualmente provável que exista uma experiência marcante por trás dessas escolhas, as quais podem ser vistas, frequentemente, como inconscientes.

Os novos meios de comunicação indicam que ainda não atingimos a fronteira do imaginário. Com sua popularização nas últimas décadas, a internet se colocou como uma nova forma de se trabalhar e se informar do mundo. Mais recentemente e mais pertinente à psicologia, contudo, é a nova forma de se relacionar que o mundo cibernético trouxe 
aos indivíduos. A esse respeito, Roesler (2008, p. 427) explica que a relação virtual é necessariamente mediada por um aparato concreto, possuindo, porém, um caráter imaginário. Há uma região nebulosa entre o real e o imaginário porque as relações experimentadas pela internet são reais do ponto de vista social e pósmoderno, embora não se apresentem inicialmente de maneira concreta. Em sua exposição, o autor ressalta que o cyberspace representa "uma tecnologia que possibilita entrar em uma imaginação interativa com outros reais e participar de uma área intermediária coletiva" (Roesler, 2008, p. 429). O intermediário parece se situar também entre consciência e inconsciente, aos modos de uma intuição que traz à consciência algum novo conteúdo a partir de um contato inexplicável com o inconsciente. De fato, a popularidade de tais formas de se relacionar parece reforçar a hipótese de uma revalorização da intuição em nossa época, o que mereceria um estudo mais detalhado por parte da psicologia analítica.

Merece destaque o fato de Roesler considerar o outro real apenas por sua existência, ainda que não seja imediata àquele que se relaciona pela internet. $\mathrm{O}$ real, para o autor, também sugere uma conexão com a materialidade da coisa. Mais ainda, quando levanta a mediação como característica da internet, esclarece-nos que tal mediação ocorre por força concreta e via sensorial. O relacionamento é predominantemente visual, o que fica mais óbvio na recente popularização de videoconferências e webcams, e usa como mediador um aparato físico claramente perceptível. Contudo, se retornarmos a Jung ([1954] 2000, p. 333), o autor nos coloca o real imediato como algo parecido com a virtualidade da internet. Segundo Jung, "esta realidade é um mundo psíquico que só nos permite tirar conclusões indiretas e hipotéticas". Dessa forma, estabelece-se uma relação entre o psíquico e o virtual, ambos campos intermediários entre o espírito e a matéria. Entre a percepção do estímulo luz e a formação da imagem luz, por exemplo, ocorre um processo psíquico inconsciente que entrega à consciência tal imagem, muito distinta e nada objetiva, como vimos, em relação à matéria perse. A apreensão da realidade material também é mediada, tanto por um fator psíquico como por um complexo sistema neuronal que faz a tradução do material nas imagens que obtemos em nossa mente. Por isso, diz Jung ([1954] 2000), pouco sabemos a respeito do que exatamente é aquilo que nos parece tão óbvio, a matéria. E também por isso, quando usamos o termo real, não pretendemos por este querer dizer qualquer coisa que se assemelhe à objetividade, à praticidade ou à precisão que nos retire a dúvida preciosa colocada pelo fato de sermos consciências necessariamente parciais e subjetivas.

Em uma perspectiva junguiana, deve-se compreender a vivência alternada entre realidade e fantasia como normal, como colocado por Jung ([1921] 2009, p. 396): “a dualidade da atitude é um fenômeno normal que só traz efeitos perniciosos quando a unilateralidade consciente é excessiva". Faz parte de nosso funcionamento psíquico habitual podermos considerar tanto a fantasia como nosso mundo físico externo. Entretanto, é necessário ir além, buscando na polaridade do real também um caminho que possa ser considerado criativo. É preciso superar o medo de incorrer no concretismo e vislumbrarmos as possibilidades simbólicas que podem ocorrer no contato com o mundo e com a experiência sensorial. Apenas desse modo pode-se tentar resgatar a fertilidade do real diante de novas experiências tão mais conectadas à virtualidade e à fantasia. De fato, é justamente na vivência do real que podemos pesquisar alternativas para conflitos que surgem juntamente a tal virtualidade, possivelmente trazidos por uma atitude demasiadamente unilateral da consciência que se fascina com essas novas modalidades de relacionamento e convenientemente se esquece da necessidade do toque, das sutilezas da vOZ e dos cheiros no contato com o outro. Um caminho para superarmos a ênfase demasiada na intuição, portanto, é a reflexão acerca de como resgatarmos, também, o viver em contato com a sensação.

\section{O cotidiano numinoso da sensaçáo}

Uma preocupação central da psicologia analítica tem sido o estudo do fenômeno assim chamado numinoso. Jung ([1938] 2004b) toma o termo emprestado de Otto Rank, conferindo a essa palavra algo de fascinação e contato com o inconsciente. O caráter do numinoso se relaciona com o que transcende a consciência e apresenta uma experiência que ora surpreende, ora apavora, considerando a característica de novidade e fascínio trazida pelo numinoso. Tacey (2006) aponta que é, de fato, a ênfase sobre esse tipo de acontecimento o que melhor define a própria psicologia analítica como abordagem teórica distinta de outras. 
Jung ([1938] 2004b), em seu estudo da religião e do numinoso, também volta à etimologia para sustentar o que considera ser uma atitude adequada diante do psíquico. O termo "religião" decorre tanto do latim religare como religere, apontando o primeiro para a palavra "religar" e o segundo para "observar". É pertinente ao estudo do psíquico a acepção de "observar cuidadosamente", como apontado por Jung ([1938] 2004b). Para o autor, apenas desse modo poderemos demonstrar uma atitude compreensiva diante do fenômeno, respeitando seus limites, possibilidades e sua complexidade própria. O observar cuidadoso requer uma postura de alteridade e a possibilidade de abertura para que possamos nos permitir ser afetados por aquilo que estamos vendo. Jung ([1938] 2004b) aponta que é comumente no fenômeno religioso, em que uma pessoa é tomada por aquilo que experiencia, que podemos discernir mais claramente a presença do numinoso. Parece-nos que, quando se fala dessa experiência, está se versando sobre algo muitas vezes invisível e além do raciocínio lógico formal humano, apelando para instâncias psíquicas diferentes. É comum, também, que o numinoso estranhamente faça sentido, ou que o indivíduo que o experimente procure fazer sentido daquilo que acabou de vivenciar.

Um olhar desatento pode trazer complicações na relação do numinoso com a função sensação. Nosso entendimento mais corriqueiro nos diz que o numinoso se apresenta à consciência, tal como o inconsciente, de um modo imaterial. A falta de cuidado pode nos levar a considerar, novamente, que estamos navegando em mares muito mais relacionados com a fantasia do que nos levar a encontrar possibilidades de novidade e descoberta naquela existência imediata a qual já estamos tão habituados. Por isso, faz-se necessário invocar a atitude de observar cuidadosamente para que possamos desvelar possibilidades criativas de encontrar aquilo que é numinoso também no concreto, no próximo e no existente.

Na mitologia grega, os deuses mais relacionados a essas questões eram mulheres e seus temas se conectavam a terra. Notoriamente, a deusa Deméter tinha sob seu controle a fertilidade, a agricultura e as estações do ano que traziam bons frutos para a colheita. É interessante ressaltar que fertilidade e colheita são palavras frequentemente associadas à criatividade. Héstia foi considerada a deusa do lar e da lareira, também relacionada a terra, ao chão e às bases. Sobre esta, Villares de Freitas (2005) afirma que focalizar, recortar e destacar-chamar atenção para a especificidade - são atributos do símbolo trazido por Héstia. O detalhe e o recorte, tanto quanto a ênfase no específico em detrimento do global, também são traços considerados como funcionamento da sensação. A autora prossegue nos dizendo que estão contidos nessa deusa também aspectos simbólicos do cotidiano. Villares de Freitas (2005, p. 136) afirma que

a deusa nos faz também considerar os afazeres domésticos, que geralmente são monótonos e repetitivos, mas trazendo-lhes uma nova luz: passamos a enxergar o quanto são estruturais, fornecem uma base sólida, são necessários e indispensáveis, e podem também ser realizados não com ênfase no aspecto obrigação, mas no da meditação que favorecem - justamente por sua insossa repetição, permitem à consciência devanear e acolher novas imagens.

O cotidiano se relaciona tanto com essa dimensão da deusa como com características comuns à função sensação. Cozinhar, limpar e algumas outras atividades são guiadas pelos nossos sentidos; são os cheiros e a visão que nos demonstram o que precisamos fazer de modo a produzir um bom prato ou considerar um objeto limpo. A autora chama a atenção para o aspecto estrutural dessas experiências. Com elas, podemos abrir espaço para o devanear e integrar novas imagens, embora primordialmente usando uma função embasada naquilo que é mais material. São as imagens e tarefas do mundo da natureza e do concreto que desvelam novas possibilidades para o indivíduo. Relevantes também são aquelas imagens que, por si só, podem evocar essas novas possibilidades: um pôr do sol estonteante, uma bela paisagem litorânea ou aquela cachoeira que nos fez parar e questionar o sentido das coisas. Tanto afazeres domésticos como paisagens naturais relacionam-se à sensação no nível da matéria e podem trazer, em si, a semente da novidade. Não podemos sucumbir à tentação de desvalorizar aquilo que é potencialmente numinoso por causa de sua característica cotidiana. De fato, existem imposições da realidade material que não podemos evitar: todos precisamos comer, estamos quase sempre de olhos abertos quando acordados e dificilmente podemos evitar ouvir certos sons. Contudo, isso não nega a possibilidade de certa refeição ou determinada música produzirem um impacto no indivíduo que poderia ser considerado numinoso. 
Desprezar a importância psíquica de um acontecimento apenas porque a classe a qual esse acontecimento pertence ocorre de maneira muito frequente não nos parece uma atitude adequada do observador cuidadoso; ao contrário, aponta para uma desvalorização da função sensação. Se hoje ouvimos música em muitos lugares a que vamos ou comemos frequentemente sem prestar atenção nos sabores, isso não deve significar que tais experiências não possam conter a possibilidade de trazer o novo à consciência, tal como visitar incríveis paisagens ou despertar para aromas e fragrâncias para os quais nunca dispensamos a devida atenção.

É importante notar que, mesmo nos exemplos citados anteriormente, estamos novamente retornando ao território das imagens da psique e das fantasias, dos devaneios e da imaginação. Como foi dito antes, é verdade que tais coisas estejam mais próximas da função intuição do que seu par complementar, a sensação. Contudo, tanto intuição e sensação parecem dizer mais sobre os pontos de origem de um fenômeno do que a experiência total de vivê-lo. Com isso, queremos dizer que a intuição e a sensação, como visto, referem-se à percepção. Afirmar isso significa também que ambas as funções são o ponto de partida para a captação daquilo que está fora do eu. A percepção é instrumento para que se comece um longo e mais complexo processamento que envolve as outras funções da consciência apontadas por Jung ([1921] 2009), daí a possibilidade da sensação evocar novas imagens psíquicas. Essa função não é imagética em si, mas pode ser o ponto de partida para que uma elaboração simbólica ocorra. A intuição, ao contrário, é uma origem pela qual se tenta vislumbrar o invisível aos olhos para que, diante de um insight, o processo de elaboração tenha início. Muitas vezes nos referimos às nossas intuições como "uma ideia que veio do nada". A função sensação, ao contrário, busca evocar tais imagens a partir da concretude da natureza, da repetição do cotidiano e da existência imediata, aquilo que lá está. É a partir dessa realidade material que esse processo mais complexo parece tomar forma, culminando em uma elaboração simbólica que também usará outras funções e a relação com o inconsciente e com os outros em seu processamento.

\section{Conclusão}

Jung ([1921] 2009) desenvolveu uma teoria de tipos psicológicos baseando-se em atitudes básicas e funções da consciência. As funções se organizam em dois eixos e, na medida em que uma extremidade do eixo está na consciência, seu oposto se encontra com igual força no inconsciente. Atualmente, ao examinarmos fenômenos como os relacionamentos virtuais, o uso consolidado da internet, a abstração requerida para os campos mais destacados das ciências naturais - como a genética e a física quântica - e a movimentação econômica baseada muito mais em construtos intelectuais e previsões financeiras sobre o futuro, supomos que nos encontramos diante de uma revalorização da função intuição. As dificuldades em se lançar o seu par oposto - a função sensação -, no inconsciente, revelam-se fatalmente naquilo que é melhor expresso na realidade material: o corpo, as tarefas manuais, as artes plásticas, os afazeres domésticos, a questão ambiental e a natureza.

Torna-se importante, assim, nos esforçarmos em uma atitude proposta por Jung ([1938] 2004b) de observar cuidadosamente aquilo a que parece não estarmos dispensando o valor devido, e buscar possibilidades criativas no exercício da função sensação. Destaca-se, primeiramente, a capacidade de lidar com a frustração, um processo que parece se iniciar quando se credita existência àquilo que aconteceu. Para Roesler (2008), também devemos notar que a realidade virtual está necessariamente mediada pela realidade material, podendo esta fornecer um contraponto que evite uma atitude excessivamente unilateral. Jung ([1921] 2009) considera desfavorável ao desenvolvimento do indivíduo tal unilateralidade, notando que a alternância entre quaisquer polaridades pode ser considerada normal, incluindo, portanto, o material e o virtual. Finalmente, Villares de Freitas (2005) aponta que as tarefas repetitivas do cotidiano, frequentemente associadas ao que é concreto, imediato e versa sobre os sentidos, como o varrer e o cozinhar, também podem oferecer uma dimensão de meditação e reflexão, promovendo o despertar de novas imagens que contribuam em favor do desenvolvimento individual.

Dessa forma, podemos ver que o funcionamento aos modos da função sensação, aquela que fala da percepção do mundo físico e próximo, pode conter possibilidades criativas que também entrem em contato com o inconsciente de maneira a trazer novos elementos para a personalidade, desvelando novos caminhos para o indivíduo. Embora seja inerente à sua função par e complementar, a intuição, o contato com o inconsciente, também há na sensação a possibilidade de tal contato no sentido do desenvolvimento pessoal. Tanto de uma forma 
como de outra podemos encontrar novos símbolos e imagens pertinentes às nossas vivências.

Os meandros do funcionamento tipológico também não são claros como gostaríamos. Formular este artigo foi uma caminhada em uma região fronteiriça, na qual procuramos ao máximo não construir raciocínios contraditórios, mas também não nos furtarmos às contradições que se apresentaram em nosso percurso. Por fazerem parte do mesmo eixo, em muitos momentos o funcionamento intuitivo e o sensorial pareciam se confundir, mesmo sendo tão claramente diferentes na maioria das vezes. Existiu uma dificuldade de termos e um receio de repetição: real, físico, material, concreto, próximo, existente, imediato, sentido e orgânico são todas palavras que podem ser facilmente mal interpretadas e vêm sendo usadas das mais diferentes maneiras na história do conhecimento. Não se pretendeu dar a elas seu significado final; propomos, alternativamente, buscar a clareza da escrita em nosso limite, de modo a tentar dialogar com o leitor da maneira mais transparente possível.

Em um encerramento que não objetiva finalizar a discussão, gostaríamos de deixar versos que estimulem a reflexão e nunca a deixem estéril. Habitar em São Paulo é entrar em contato com a concretude de modo simbólico ou objetivo a todo instante. Sobre a possibilidade de evocar imagens a partir da função sensação, falou melhor que nós Caetano:

Alguma coisa acontece no meu coração Que só quando cruza a Ipiranga e a Avenida São João É que quando eu cheguei por aqui eu nada entendi Da dura poesia concreta de tuas esquinas Da deselegância discreta de tuas meninas...

$$
\text { (Caetano Veloso, Sampa) }
$$

\section{Referências}

Bachelard, G. (2006). A poética do espaço. São Paulo: Martins Fontes.

De Masi, D. (2000). O ócio criativo. Rio de Janeiro: Sextante.

Freud, S. (2001). Esboço de psicanálise. Rio de Janeiro: Imago.

Hauke, C. (2003). Jung and the postmodern. Londres: Routledge.
Houaiss, A. (2001). Dicionário Houaiss da Língua Portuguesa. Rio de Janeiro: Objetiva.

Jung, C. G. (1992). Aion: Um estudo sobre o simbolismo do si-mesmo. Petrópolis: Vozes. (Original publicado em 1951).

Jung, C. G. (2000). A natureza da psique. Petrópolis: Vozes. (Original publicado em 1954).

Jung, C. G. (2002). A prática da psicoterapia. Petrópolis: Vozes. (Original publicado em 1966).

Jung, C. G. (2004a). Psicologia do inconsciente. Petrópolis: Vozes. (Original publicado em 1912).

Jung, C. G. (2004b). Psicologia e religião. Petrópolis: Vozes. (Original publicado em 1938).

Jung, C. G. (2007). O eu e o inconsciente. Petrópolis: Vozes. (Original publicado em 1971).

Jung, C. G. (2009). Tipos psicológicos. Petrópolis: Vozes. (Original publicado em 1921).

Lehman, Y. P. (1999). Não sei que profissão escolher. São Paulo: Moderna.

Ramos, D. G. (2006). A psique do corpo. São Paulo: Summus.

Roesler, C. (2008). The self in cyberspace: Identity formation in postmodern societies and Jung's Self as an objective psyche. Journal of Analytical Psychology, 53(3), 421-436.

Tacey, D. (2006). The idea of the numinous, contemporary jungian and psychoanalytic perspectives. Londres: Routledge.

Veloso, C. (1978). Sampa [DVD]. Brasil: Universal Music DVD (2007).

Villares de Freitas, L. (2005). O calor e a luz de héstia: Sua presença nos grupos vivenciais [Edição Especial]. Cadernos de Educação UNIC, 131-145.

Von Franz, M. L. (2004). Psicoterapia. São Paulo: Paulus.

Whitmont, E. C. (1991). O retorno da deusa. São Paulo: Summus.

Recebido: 08/04/2010

Received: 04/08/2010

Aprovado: 30/06/2010

Approved: 06/30/2010 